\title{
Why do People in Bali Meet Traditional Healer?
}

\author{
$1^{\text {st }} \mathrm{Ni}$ Made Swasti Wulanyani* \\ Department of Psychology \\ Udayana University \\ Bali, Indonesia \\ swastiwulan@unud.ac.id \\ $3^{\text {rd }}$ Made Padma Dewi Bajirani \\ Department of Psychology \\ Udayana University \\ Bali, Indonesia \\ bajirani@gmail.com
}

\author{
$2^{\text {nd }}$ Kadek Meri Wahyuni \\ Department of Psychology \\ Udayana University \\ Bali, Indonesia \\ meriwahyuni15@gmail.com \\ $4^{\text {th }}$ Aria Saloka Immanuel \\ Department of Psychology \\ Udayana University \\ Bali, Indonesia \\ ariaimmanuel@gmail.com
}

\begin{abstract}
The Balinese have a unique belief in daily life including their behavior to seek various kind of health care either to professionals (medical doctor, psychologist, psychiatrist, etc.) or traditional healer (balian). Balian represents a person who is considered to have the power to heal illness. Balinese have no hesitation to meet traditional healer in order to get supplementary medical treatment for physical illness and psychological problems. Aim of this research was to explore the factors that influence Balinese in seeking treatment provided by traditional healer. This study was conducted using qualitative approach, and was divided into two phase, i.e. online survey phase (study 1) and interview phase (study 2). Participant of the studies were 118 Balinese (study 1) and 6 Balinese (study 2). Result of the study was Balinese decision to seek help from balian affected by many factors. In Theory of Planned Behavior (TPB), participant's behavior related to their individual belief about the positive impact after receiving treatment balian as attitude toward behavior. They had familial belief and family support as subjective norm that affect their decision to meet balian. Participant in this study also shown that they did not find difficulties to seek information or help from balian which illustrated the perceived behavioral control in TPB. For instance, individual and familial belief, family support, and perceived impact from balian played important role to Balinese behavior to seek health treatment from balian.
\end{abstract}

Keywords-Bali, balian, traditional healer, health seeking behavior, theory of planned behavior

\section{INTRODUCTION}

The presence of traditional medicine spreads all over the world. The phenomenon of seeking help from traditional healer's power in solving various problems, that exist in the society, can be reached all over the whole world. The highest order of appearance is in the North American Indians, Chinese immigrants in Canada, Pakistanis and Muslims in Britain, Bangladeshis in London, Turkish in Germany and Asian refugees in the United States. The legitimacy and the status of traditional healer in the health system are still being debated, but up to now there are 31 countries that have recognized the potential of traditional healers in overcoming mental health problems and have tried to collaborate between traditional healers and modern health care systems for example Indonesia, South Africa, Uganda, Papua New Guinea, New Zealand, Canada and the United States [1].
Indonesia is one of the countries that makes traditional medicine an alternative choice in treating patients. In 2013, it was noted that in Indonesia over $30.4 \%$ of families sought traditional medicine [2]. Lack of medical treatment accessibility in a certain area is a factor that contribute Indonesian to seek help from traditional healer. Data from the Central Statistics Agency (Badan Pusat Statistik) Republic of Indonesia in 2018 showed that over $4.91 \%$ of Indonesian lacked of health services [3]. Seeking help from traditional healer behavior is higher than the rate of absence of medical services in Indonesia, this showed another factor might influence Indonesian to seek help from traditional healer. Khair [4] stated that decision to seek help from traditional healer can be caused by beliefs that already grown-up in society. The beliefs comprehended illnesses, both physical and mental illness (ranged from mild to severe level) was caused by supernatural beings, so the concept of pain and how to cure the pain depends on the cultural definitions.

Traditional healer who is very close to the culture of Indonesian society is not a phenomenon that has just happened, this practice has been passed down from generation to generation. Traditional healing is growing in Bali. Seeking help to traditional healer among Balinese regarded as a habit. Most of Balinese comes to traditional healer with various reasons. The Balinese call traditional healer by the name of balian whose treatment is also known as usada bali. Types of balian as Usada Bali practitioners in the book Heilkunde und Volkstum [5] and Usada Bali [6]. There are a) balian ketakson is a person who has the ability to treat by possessing a supernatural force that helps him treat illness; b.) balian kapican is a person who uses magical objects obtained from paica (gift of supernatural objects from the subconscious); c.) balian usada is a person who really learns from a balian teacher or a qualified person based on lontar usada bali; and d.) balian campuran are people who use all methods in treating clients and their abilities are obtained from various ways such as ketakson, supernatural objects, usada and so on [7]. Traditional healer practice uses variety of methods and depends on their types. Balian use combined method such as herbal medicine (plant-based or animal-based) and water and writing media (also known as lontar). There's also traditional healer who uses the power of mind to help patients. 
The recognition and appreciation of the Balinese people for balian are still very high [8]. This condition makes balian practices still lasting and demanding for various groups. Based on data from the Central Statistics Agency in 2018, the medical health accessibility in Bali was improvised. According to these data, health services are quite good and easily accessible by the community [3]. The Balinese is still seeking for traditional healing when overcoming health problems although the Balinese still have access to health services. Therefore, this study aimed to explore the reasons of Balinese who seek help from traditional healer.

\section{METHOD}

This study consisted two main processes. We began the study 1, with online survey using Google forms as a survey medium. Online survey was administered to 146 participants. We excluded 28 participants who have not met balian in the rest of their life. Study 2 begun with randomly selecting 12 participants to be interviewed. Only 6 participants consented to interview process.

The study 1 focus on online survey about experience of meeting balian, affective aspects (feeling and thoughts) while meeting balian, family perceptions and support, decision to meet balian, and perception to suggest others to meet balian. The study 2 focus on the interview of people who have had experience to meet balian for treatment.

\section{A. Participant}

Participant on the study 1 consisted 118 people who live in Bali. Demographic data can be seen in table 1. Participants on the study 1 were 58 men and 60 women, aged from 17 to 60 years old $($ mean $=31.50, S D=13,076)$. Living duration in Bali ranged from 1 to 60 years (mean $=29.36, S D=14.10)$. Level of education ranged from elementary school $(n=2)$, junior high school $(n=5)$, senior high school $(n=60)$, diploma $(n=9)$, bachelor $(n=37)$, and master $(n=5)$.

Participants on the study 2 were randomly selected by living duration, level of education, and ages. Demographic data of participants in study 2 can be seen in the table 1 .

Table 1. Demographic data

\begin{tabular}{lllll}
\hline Participant & Sex & Age & $\begin{array}{l}\text { Living } \\
\text { Duration }\end{array}$ & $\begin{array}{l}\text { Level of } \\
\text { Education }\end{array}$ \\
\hline 1 & Female & 21 & 3 years & $\begin{array}{l}\text { Senior High } \\
\text { School }\end{array}$ \\
\hline 2 & Male & 54 & 10 years & Master \\
\hline 3 & Female & 20 & 20 years & $\begin{array}{l}\text { Senior High } \\
\text { School }\end{array}$ \\
\hline 4 & Male & 25 & 25 years & Bachelor \\
\hline 5 & Male & 28 & 28 years & Bachelor \\
\hline 6 & Male & 54 & 38 years & Bachelor \\
\hline
\end{tabular}

\section{B. Instrument}

This study used two instruments to draw information about the factor affecting participants to meet balian. Online survey questionnaire consisted 11 items that designed to explore participant's experience of meeting balian, participant's affective aspects (feeling and thoughts) while meeting balian, participant's family perception and support, participant's decision process to meet balian, and participant's perception to suggest others to meet balian. Interview guideline also used in this study. Interview guideline was delivered participants to get deeper understanding about factors affecting participants to meet balian. Interview guidelines presented on table 2 .

\section{Data Analysis}

Data was analyzed by descriptive technique and coding analysis. In keeping with this methodology, the transcripts were read and re-read to obtain immersion and a good understanding of the data. Open coding was then conducted by a single coder to categorize data and organize it into themes of framework.

Table 2. Survey Questions

\begin{tabular}{|l|}
\hline Survey Questions \\
“Have you met Balian?" \\
"What conditions that encourage you to meet Balian?" \\
“How often you meet Balian?" \\
"Where did you get information about Balian?" \\
"How do you feel when you meet Balian?" \\
"How do your family react to your decision to meet Balian?" \\
"If you are under specific health problem, will you meet Balian?" \\
"Will you suggest your relatives or friends to meet Balian?"
\end{tabular}

\section{RESULT}

\section{A. Number of Balians Met by Participant}

Table 3. Number of Balians met by participant

\begin{tabular}{lcc}
\hline$\quad$ Number of Balian & $(n)$ & Percentage \\
\hline 1 & 25 & $21 \%$ \\
$2-4$ & 69 & $58 \%$ \\
$5-7$ & 7 & $5.9 \%$ \\
More than 7 & 18 & $18 \%$ \\
\hline
\end{tabular}

According to table 3, 69 participants (58\%) met two to four balians in the rest of their life. Our interview result (in the study 2) explained participant tends to seek another balian if they don't feel any progress.

\section{B. Sources Provided Information about Balian}

Table 4. Information Sources

\begin{tabular}{lcc}
\hline \multicolumn{1}{c}{ Sources } & (n) out of & Percentage \\
& 119 & \\
\hline Family & 92 & $77.31 \%$ \\
Friends/Colleagues & 27 & $22.68 \%$ \\
Media (Electronic-based / & 11 & $9.24 \%$
\end{tabular}

Paper-based)

In the study 1, we found that 92 participants $(77.31 \%)$ got information about balian from family, 27 participants (22.68\%) from friends/colleagues, and 11 participants $(9.24 \%)$ from media (electronic-based or paper-based). According to study 1 result, most of participants got information about traditional healing and balian from their family and 
friends. Interview with participant also revealed information that most of them got information from their nuclear family (parents) and extended family (aunt, grandmother).

I had met Balian cause my parent [mother] suggested me-Participant 3.

[I got information about balian] from my Grandmother - Participant 4.

My aunt suggested me - Participant 1

In similar condition, some of participants got information from working partner in the office or neighbor from the society. A few participants knew balian when they accompanied their family/friends or they heard someone's were getting better condition after seeing balian.

\section{Motivation to Meet Balians}

Table 5. Motivation to Meet Balian

\begin{tabular}{lcc}
\multicolumn{1}{c}{ Sources } & $(n)$ out of & Percentage \\
\cline { 2 - 2 } & 119 & \\
Consultation & 72 & $60.5 \%$ \\
Psychological Discomforts & 61 & $51.3 \%$ \\
Physical Illness & 53 & $44.5 \%$ \\
Others & & \\
$\quad$ Accompanying family & 3 & $2.5 \%$ \\
$\quad$ Asked by family & $\underline{1.7 \%}$ \\
\hline
\end{tabular}

Participants showed various motives to meet balians. Most of them were triggered by their needs to consult (60.5\%), their feeling of psychological discomforts (51.3\%), and physical illness $(44.5 \%)$.

Topics consulted by participants were when will the good day to celebrate, praise, or pray, their fortune in romantic relationship or business.

..... not seeking for medical treatment. I just wanted to ask. Asked about good day for do something or asked about names. My sister and her fiancée are matched due to their name - Participant 1.

On the other side, psychological discomforts might trigger participant to meet balian were feeling of disorientation, difficulty to sustain attention, and feeling too much thinking/overthinking. Some of psychological discomfort feelings are related to physical problems. Physical problems encourage them to meet balian were difficulties to mobile, having itch, and burping.

Participants tend to meet balian if they have feeling of discomfort or condition that couldn't be explained by professional healthcare (medical doctor, specialized medical doctor). Minimum medical improvement after taking medical treatment also played a role to encourage them to meet balian. Participants also showed desire to see balian if their assumptions that it was non-medical disease. Participant stated that there's non-medical condition (condition couldn't be explained in medical terms) and sometimes it occurred by someone else's spells (black magic).

Yes, I will, if I have non-medical disease, like bebai (Balinese term for disease that affected by someone else's influence or black magic) - Participant 3.

\section{Family Reactions to Participant's Decision}

Table 6. Family reactions

\begin{tabular}{lcc}
\multicolumn{1}{c}{ Reactions } & (n) out of & Percentage \\
\cline { 2 - 2 } Supporting & 119 & \\
Neutral & 94 & $78.99 \%$ \\
\hline
\end{tabular}

Family reactions to participant's decision to meet balian are divided into supportive reactions (78.99\%) and neutral reactions $(18.49 \%)$. Support given by their family including physical presence (accompanying participant to see balian), emotional support (reminding participants to see balian and asking the post-treatment effect), and informational support (giving information or suggestion).

Strong familial belief and tradition can be seen from family who live in Bali, even though many balian existing in Java. Participant's family, who live in Java, didn't show belief as strong as her family in Bali. She got information and encouraged to see balians from her family in Bali.

Neutral reactions were also showed by participants to support their family to seek treatment from balian if the condition can't be explained by medical professional.

We will support [traditional healer treatment]. but, we still prioritize medical treatment. If it can't be medically explained, then we will seek treatment from balian. Participant 5.

\section{E. Impact of Meeting Balian}

Table 7. Impact while and after meeting balian

\begin{tabular}{|c|c|c|}
\hline Impact & $\begin{array}{l}\text { (n) out of } \\
105\end{array}$ & Percentage \\
\hline Positive & 56 & $53.33 \%$ \\
\hline Neutral & 36 & $34.29 \%$ \\
\hline Negative & 13 & $12.38 \%$ \\
\hline
\end{tabular}

\section{Positive Impact}

About $53.33 \%$ participants felt positive impact while and after taking treatment from balian. Participants also realized physical condition improvement after treatment.

Participants who felt positive impacts tend to feel positive emotions (happy, comfortable, relaxed, calmed, sure, and confident)

I had trust, got calm, and felt comfortable - Participant 3.

Some participants were aware that decision to meet balian is related to their beliefs. Participants who met balian by his/her own decision tend to feel sure with his/her own decision to meet balian. Feeling sure by the participant depends on belief. They believe that traditional medicine is a part of culture and belief towards life, even though it's difficult to be scientifically understood.

Yes, it [decision to meet traditional healer] had correlated with belief. Believe it first, then we can do it. It's difficult to be scientifically explained - Participant 6.

This tradition and belief inherently become familial belief, not only for participant. All family member will support participant to see balian. On the other hand, Participant started to believe when the treatment gave positive impact on his 
family health condition.

At first, I was doubt and confused. I couldn't understand, because my family asked me to accompany them. But then I believe when there was a change [positive change]. - Participant 5.

Participant believed the importance of balancing traditional healing with modern medicine (in terms of medical treatment). Traditional healing would be part of comprehensive healing for his family or beloved one.

... considered it [seeking help from traditional healer] as part of effort to support family or beloved one, so they will get comprehensive treatment - Participant 5.

\section{Negative Impact}

$12.38 \% \%$ of participants felt negative impact while and after taking treatment from balian. Participants who felt negative impact reported negative emotions (scared, mystical, goosebumps, tensed, and hideous).

I became scared while I told to see that balian more and more. Cause, it feels like, I don't do anything but I was wrong. Then, there was part of me that feel uncomfortable. What If I had to see balian in three times to purify myself - Participant 1.

Participants also didn't realize any progress in their physical condition. Participants who feel doubt and confused after meeting balian, tend to seek another balian or continuing medical/psychological treatment.

\section{Neutral Impact}

$34.29 \%$ participants were categorized as neutral impact because they reported neutral feelings (didn't feel anything). Participants started to be sure when balian can guess his condition correctly. They will seek another balian when the previous balian's suggestion or explanation triggered feeling of discomfort and risk to break family relations. They seek another balian in order to keep harmonious relation with the family (nuclear family and extended family). He's also willing to meet balian who lived far away from his home.

If [balian's] guesses were correct, I believed him. But, if the guesses weren't match and triggered conflict in my family, I will look for another balian, even the balian lives far away from my house - Participant 6.

All of the participant also stated that they also continuing medical treatment while taking suggestion and advice from balian.

\section{F. Will Participant Suggest Others to Meet Balian?}

Table 8. Participant suggestiveness

\begin{tabular}{|c|c|c|}
\hline Suggestiveness & $(n)$ & $\overline{\text { Percentage }}$ \\
\hline Yes & 19 & $15.96 \%$ \\
\hline Maybe & 66 & $55.46 \%$ \\
\hline No & 34 & $28.57 \%$ \\
\hline
\end{tabular}

When we asked "Will you suggest your relatives or friends to meet Balian?", around 55.46\% participants chose "maybe" as their answers. Participants tend to suggest relative or family in specific terms and condition. For instances: 1) Participant and relative or family have similar belief in traditional healing; 2) Relative or family have taken medical treatment but has never recovered or has never felt improvement on their condition.

Around $28.57 \%$ participants refused to suggest others (family or friends) to meet balian. This refusal appears because of participant's respect to the others belief. Participants argued that taking treatment provided by balian is part of someone else's belief and human rights. Participant wasn't sure that balian can cure their problems. Participant ever read that people can be cured is rely on beliefs.

[decision to seek help from balian] is privacy. If he/she decide to meet balian, it's his/her rights. - Participant 1.

Seeing Balian depends on people's beliefs. I don't know exactly, will it able to cure people or not. I've read that [people who seek treatment from balian] will be cured by their own belief-Participant 3

In another viewpoint, around $15.96 \%$ participants would like to suggest others (family or friends) to meet balian. Participant expressed willingness to suggest others to meet balian after they have been cured.

after we've cured [by balian], our relatives would asked which balian that I have met. It becomes word of mouth discussion - Participant 2.

\section{DISCUSSION}

Ajzen argued that cognitive self-regulation played important role to predict individual's behavior in specific situations. According to Theory of Planned Behavior (TPB), individual occurring behavior affected by dispositional factor called intention [9]. These are three dispositional determinants of intention such as attitude toward the behavior, subjective norm, and perceived behavioral control which played important role to predict intention and behavior.

The first is the attitude toward the behavior refers to the degree to which a person's evaluation of the behavior. Second, subjective norm refers to social pressure perceived by a person to perform or not to perform the behavior. The last predictor is perceived behavioral control which refers to perceived ease or difficulty of performing the behavior [9]. Perceived behavioral control terminology is similar with Bandura's self- efficacy concept which focus on a person's perception towards his/her ability to perform a certain behavior.

Theory of Planned Behavior is one framework that can describe the dynamics of the results in this study. In the determinant of attitude toward the behavior is associated with individual's positive or negative beliefs about performing a specific behavior [9]. This condition we can see that the evaluation of participants on the positive, neutral, and negative impacts that will be obtained after visiting balian. More than half of the participants $(53.3 \%)$ felt the positive effects seen from the emergence of positive emotions such as they feel happy, comfortable, relaxed, calm, sure, and confident. This positive condition also supports participants' behavior to repeat and or suggest relatives to come to the traditional healer.

These finding are also in line with research conducted by Greensky who shows the role of traditional healer in the treatment of patients with chronic diseases among American Indian patients. In that study, almost all of the participants 
received services from a traditional healer in the pain treatment program and felt an improvement in theirpain. This is supported by the positive impact received because of the mental and spiritual support from traditional healer [10], blessing and strengthening amid family difficulties [11], significant social support (family, friends, and community) which can be healing process for patients [12].

Attitude toward the behavior is also illustrated in how far the participants' evaluation of the behavior [9]. Dzulkipli statistically found that there was a significant relationship between attitudes and the intensity of a person to purchase complementary and alternative medicine in Malaysia [13]. Other previous studies showed that the belief in visiting traditional healers in American Indians has also been familiar since they were children or adolescents [10].

American Natives or American Indians often visit traditional health practices that were strongly associated with cultural affiliation [12]. Ikram \& Ghani in their research found that there is a link between Malaysian culture that reinforces beliefs and trust in complementary and alternative medicine [14]. This is further strengthened when individuals have visited medical services but have not shown improvement after undergoing a few treatments [15]. Integrative perspective also can be used in this view, while both healthcare professionals and traditional healers are included in social activities and also reflect particular cultural values [16].

In this research, some participants were aware that the decision to meet traditional healer is related to their beliefs. When they go to traditional healer by own decisions, they tend to feel sure that depends on their belief. They believed that traditional medicine is a part of culture and belief towards life, even though it is quite difficult to be explained or understood by science. This study also showed that most of the participants visited the traditional healer because they have physical illness such as difficulties to mobile, having itch, and burping. They also had medical treatment but showed no improvement.

Based on the theory of planned behavior [17] a person's behavior towards a behavior is influenced by subjective norms, the individual's perception of the expectations of people who influence in the surrounding environment. Relationships can also be horizontal or vertical. Vertical relationships occur as in the relationship between parent and child. This expectation can be injunctive so that they tend to be demanding for compliance or not [18]. The results are also in line with the findings of previous studies conducted by Muhammad, Merriam, \& Suhami where breast cancer patients in Malaysia tend to meet traditional healers because they get recommendations from family and friends [19]. Some of the participants got support and asked to try coming to traditional healer. In addition, there also sanction from the family both of parents or spouse. This condition made the family have a strong role to motivate participants to meet traditional healer.

Related to subjective norm, this research found another factor that influence participants to visit the traditional healer is the belief of the family or the information provided by the family. The first study (survey) showed that more than seventy percent of participants received information about the traditional healer visited from their families. The tradition of meeting a traditional healer when in trouble has also become a belief of the family and the whole family of the participants interviewed showed a positive attitude or support to visit the traditional healer. Some participants also explained that the things that made them sure to come to the traditional healer were directions from the family or beliefs from the family for generations. Participants also felt satisfied and had done the right thing by fulfilling the desire of the family to visit the balian. Visiting balian also shown as an effort to obtain comprehensive input or treatment that will be appreciated by the family and the environment. Even ancestors will be considered calmer in the case of participants who ask the cause of his father's death.

Further on another aspect, perceived behavioral control is the individual's perception of how easy or difficult it is to realize the behavior [17]. This research shows that some of the participants believe that meeting a balian will help them solve their problems. This belief will be stronger when after participants see the positive impact of meeting with balian on improving the condition of his family. Someone with high behavioral control will know the actions that need to be taken when experiencing difficulties. He knows about a number of things that need to be prepared, and to whom he asks for help when he has difficulties so he will continue to try harder. When a participant is dissatisfied with the services of a courier, he / she easily decides to look for another recipient even if the location is far from where he lives.

\section{CONCLUSION}

People live in Bali have unique behavior in their daily life. One of the behaviors is meet the traditional healer that called as Balian for consultation, when they have psychological discomfort, physical illness, also for other condition such as accompanied their family or asked by family. This behavior related with their attitude because of their personal belief and positive impact expectation after met the traditional healer. This belief also in line with the vertical subjective norm in Bali. The behavior People who live in Bali tend to meet traditional healer influenced by family as their environment. People live in Bali did not find difficulties to meet Balian that describe the perceived behavioral control in TPB.

\section{REFERENCES}

[1] Nortje, G., Oladeji, B., Gureje, O., \& Seedat, S. Effectiveness of traditional healers in treating mental disorders: a systematic review. The Lancet Psychiatry, 3(2), 2016, 154-170.

[2] Nurhayati, N., \& Widowati, L. The use of traditional health care among Indonesian Family. Health Science Journal of Indonesia, 8(1), 2017, 3035

[3] Badan Pusat Statistik. Unmet Need Pelayanan Kesehatan Menurut Provinsi, 2015-2018. Jakarta : Badan Pusat Statistik.

[4] Khair, N. Ritual Penyembuhan dalam Shamanic Psychotherapy (Telaah Terapi Budaya di Nusantara). Buletin Psikologi, 23(2), 2015,82-91.

[5] Weck, Wolfgang. Heilkunde und Volkstum auf Bali, 1976. Jakarta : PT. Intermasa.

[6] Nala, N. Usada Bali, 1993. Denpasar : PT. Upada Sastra.

[7] Suatama, I. B., Kumbara, A. A. N. A., \& Dewi, A. A. S. K. Commodification of usada bali : between profit-oriented and negotiation of sasana balian. International Journal of Social Sciences and Humanities, 3(2), 2019, 136-144. doi 
doi.org/10.29332/ijssh.v3n2.300

[8] Prastika, N. YOGA SASTRA. Dharmasmrti: Jurnal Ilmu Agama Dan Kebudayaan, 17(2), 2017, 11-19. doi : doi.org/10.32795/ds.v17i02.84

[9] I. Azjen., The Theory of Planned Behavior. Organizational Behavior and Human Decision Processes 50, 1991, 179-211.

[10] C. Greensky, M. A. Stapleton, K. Walsh, L. Gibbs, J. Abrahamson, D.M. Finnie, ... W.M. Hooten. A Qualitative Study of Traditional Healing Practices among American Indians with Chronic Pain. Pain Medicine, 15(10), 2014, pp.1795-1802. doi:10.1111/pme.12488

[11] C. Kim \& Y.S. Kwok, Navajo use of native healers. ArchIntern Med; 1998, 158:2245-9.

[12] D. Buchwald, J. Beals, \& S.M. Manson. Use of Traditional Health Practices Among Native Americans in a Primary Care Setting. Medical Care, 38(12), 2000, pp.1191-1199. doi:10.1097/00005650200012000-00006

[13] M.R. Dzulkipli, N.A. Azizam, S.N. Maon, N.I Aziz, N.M. Azlan, N.S.Razak, N.H. Azmi, \& N.S. Roslan. Application of Theory of Planned Behavior to Predict the Intention to Purchase Complementary and Alternative Medicine. International Tourism and Hospitality Journal 2(3): 1-07 (2019). ISSN: 2616-4701.

[14] R.R.R. Ikram \& M.K.A. Ghani. An overview of traditional malay medicine in the Malaysian Healthcare System. Journal of Applied Sciences, 15(5), 2015, 723-727. doi:10.3923/jas.2015.723.727

[15] M. Farooqui, M.A. Hassali, A.K.A. Shatar, M.A. Farooqui, F. Saleem, N.U. Haq, \& C.N. Othman. Use of complementary and alternative medicines among Malaysian cancer patients: A descriptives study. Journal of Traditional and Complementary Medicine, 6, 2016, 321326. doi:dx.doi.org/10/1016/j.jtcme.2014.12.008

[16] D.J. Stein. Philosophy of psychopharmacology: smart pills, happy pills, and pep pills. 2008. Cambridge, UK.: New York: Cambridge University Press

[17] I. Ajzen. Attitudes, Personality and Behavior, (2 edition), Berkshire, 2005, UK: Open University Press-McGraw Hill Education.

[18] N. Ramdhani. Penyusunan Alat Ukur Berbasis Theory Planned Behavior. Buleten Psikologi, 19(2), 2011, 55-69.

[19] M. Muhamad, S. Merriam, \& N. Suhami. Why Breast Cancer Patients Seek Traditional Healers. International Journal of Breast Cancer, 2012, 1-9. doi:10.1155/2012/689168 